\title{
Futebol e violência: Freud explica?
}

\section{Soccer and violence: Can Freud explain?}

\author{
Gustavo Hermínio Salati Marcondes de Moraes* \\ Fundação Getúlio Vargas - FGV, São Paulo, São Paulo, Brasil \\ Olga Maria Salati Marcondes de Moraes** \\ Secretaria de Estado da Educação de São Paulo, São Paulo, São Paulo, Brasil
}

\begin{abstract}
RESUMO
Neste artigo, buscaremos refletir sobre a análise de comportamentos que transformam o lazer propiciado pelos jogos de futebol em espetáculo de violência e vandalismo. Embora possa praticar atos de vandalismo, quando isolado, o indivíduo normalmente participa dessas ações violentas quando em grupos. Isto se explica pela possibilidade de utilizar a proteção do grupo para se fortalecer, superando o medo. Dessa forma, são explicados os comportamentos agressivos das torcidas de futebol. A impunidade e a ilegalidade reinantes na sociedade atual, caracterizada pela satisfação pessoal, busca de prazer e realização de desejos, vêm potencializando tais fatos. Estudos demonstram que diversos aspectos das teorias de Freud podem ser associados às questões discutidas nesse ensaio sobre causas da violência no futebol e seu desenvolvimento, em especial no contexto das torcidas organizadas; tais questões devem ser pensadas para além do âmbito subjetivo, também no contexto sócio-histórico, dada a relevância da totalidade dos aspectos sociais, culturais, econômicos, bem como da educação.
\end{abstract}

Palavras-chave: Violência, futebol, comportamento, Freud.

\begin{abstract}
In this article, we reflect on the analysis of behaviors that transform the leisure afforded by the soccer into a spectacle of violence and vandalism. Although the individual may commit acts of vandalism alone, usually participate in these violent actions in groups. This fact, common among soccer fans, may be explained by the possibility of using the protection and enhancement, when they are in a group. The impunity and lawlessness prevailing in modern society characterized by personal satisfaction, pleasure, and fulfillment of desires, are leveraging these facts. Studies show that many aspects of Freud's theories may be related to the issues discussed in this essay on the causes of violence and its development, particularly in the context of pep rallies, such issues should be thought beyond the subjective, also in the socio-historical given the importance of all social, cultural, economic, and education.
\end{abstract}

Keywords: Violence, soccer, behavior, Freud. 


\section{I ntrodução}

Em tempos de Copa do Mundo nosso país é tomado por certa magia, que envolve e paralisa boa parcela da população.

A tabela de jogos torna-se o parâmetro que determina a nova divisão do tempo e horários de trabalho, comércio, indústrias e escolas refletem e se adaptam à exibição da seleção do país.

Administradores reúnem-se aos trabalhadores das empresas, organizando antecipadamente rodízios e plantões dos setores, facilitando o acompanhamento dos jogos. Nas livrarias, vários novos títulos sobre futebol podem ser encontrados, as coleções de figurinhas e álbuns exibindo fotos e biografias dos jogadores da seleção ganham realce e disparam nas vendas.

O Brasil destaca-se internacionalmente como celeiro de jogadores profissionais. Para Assis (2008), o futebol é mais que um simples esporte com regras, técnicas e táticas. A cultura é impregnada de valores e símbolos afetos a esse esporte: filhos são presenteados ao nascer com camisetas do time que herdarão como torcedores, as diferentes mídias dedicam grande parte do seu trabalho acompanhando tais atividades, o grande "rei" de gerações é Pelé, são recorrentes as manifestações culturais relacionadas a esse tema e o recente Museu do Futebol/SP já desponta como um dos mais visitados do país. Tais fatores são suficientes para classificar o Brasil como o país do futebol. Entretanto, paralelamente aos momentos de alegrias, satisfação e lazer proporcionados pelas equipes dos times, são recorrentes as manifestações de violência e vandalismo, transformando estádios em templos de tensão social.

Neste ensaio, buscaremos na bibliografia especializada, verificar o surgimento, e teorias que subsidiem análise de tais comportamentos que acabam transformando a alegria do futebol em espetáculo de agressão.

\section{Violência no Futebol: gênese}

Murphy, Williams e Dunnig (1994) apontam que futebol e violência apresentam-se associados desde remotos tempos, nos âmbitos nacional e mundial, com registros recorrentes de violência entre torcedores na história do futebol. Estes autores ressaltam que o fato novo refere-se às torcidas organizadas e à concentração de jovens em torno delas.

Murad (2007) registra o aparecimento do fenômeno do hooliganismo por volta de 1870/1880 na Inglaterra, como presença preocupante dos atos violentos nos espaços futebolísticos, registrando: 
O primeiro grande golpe sofrido pelo futebol foi em 5 de abril de 1902, em Ibrix Park, campo da equipe escocesa Glasgow Dangers, com o saldo de 25 mortos e 483 feridos.

Na trajetória da história do futebol, destaca-se ainda a conhecida tragédia de Heysel, ocorrida em Bruxelas, em 1985, que contabilizou centenas de feridos e 39 mortos, atraindo a atenção mundial, provocando a estruturação dos comitês em diferentes países, visando a criação de legislação específica aplicável aos atos de violência. Neste sentido, pode-se citar o Comitê Permanente da Convenção da Europa (1985), Comissão Nacional contra a violência nos Espetáculos Esportivos da Espanha (1990), Associação Francesa para o Desporto Sem Violência e para o Fair Play (1992), Conselho Nacional contra a Violência no Desporto de Portugal (1998). Há no Brasil, o Estatuto do Torcedor do Futebol - Lei № 10671/2003, que, segundo Reis (2006), "é um instrumento legal fundamental para os trabalhos de prevenção da violência relacionada aos espetáculos esportivos".

Autores como Pimenta (1997) e Murad (2007) compartilham a idéia de que as torcidas organizadas, embora criadas pelas próprias torcidas para se constituir em espaços de reunião e congraçamento dos torcedores, têm-se associado frequentemente com as ocorrências de violência no futebol. Reis (2006) considera que por volta de 1940 o objetivo das torcidas era divertir-se e torcer pelos times, durante as partidas.

Em 1980 foram registradas pela mídia comportamentos envolvendo agressões e demonstração de truculência entre torcedores, não comuns até então. A frustração pela vitória não conseguida pelo time é apontada como a gênese das brigas e destruições dos próprios municipais e dos meios de transporte e locomoção (RODRIGUES FILHO, 1964; BUFFORD, 1992; SANTOS, 2004; PIMENTA, 1997).

Murad (2007) e Pimenta (1997) citam que na década de 1990 é que as torcidas organizadas ganham maior atenção na mídia e imprensa especializada, por transformarem as partidas de seus times em espaços de tensão social. Para Lerner (1996) a reincidência de confrontos é registrada e os materiais utilizados para ataque e defesa tornaram-se mais contundentes.

Mesmo assim, para Murad (2007) e Pimenta (1997), as torcidas organizadas continuam contagiando e atraindo para os estádios uma massa anônima que usa de uniformes, faixas, músicas, coreografias, fogos de artifício, buscando congratular-se com os seus times, o que nem sempre ocorre. Reis (2006) destaca, como ponto máximo da violência no futebol no Brasil, o episódio conhecido como Guerra do Pacaembu, em 1996, em São Paulo, que redundou no fechamento das torcidas organizadas pela justiça.

Marin (2002) salienta que, com relação às torcidas organizadas, jovens "vestem" uma camisa e vão aos campos como participam de 
uma luta, e em nome desta luta vão até a morte se preciso semelhante a um vale tudo. Como analisar a presença de tal violência associada ao futebol?

\section{Futebol e violência: reflexões}

Expressão da sociedade brasileira, o esporte futebolístico merece ser estudado como tal, por permitir, por meio dele, que o povo se apresente e se desenvolva, numa manifestação que mescla emoção e beleza, fascinando milhares de pessoas, não só no Brasil como em todo mundo. Mesmo com a violência verbal e/ou física presentemente observada nos estádios e em seu entorno, o torcedor pode ser considerado parte essencial desse esporte, tornando o futebol um evento ainda mais admirável. Como ressalta Prado (1994):

[...] há poucos prazeres comparáveis ao de pular e gritar com a multidão comemorando um gol que passa a ser de todos, por direito de contigüidade emocional. (PRADO, 1994, p. 22).

Permitindo ao torcedor vivenciar emoções associadas à sua vida cotidiana, o futebol proporciona também expressões só possíveis no contexto em que se desenrola. A torcida de futebol parece realmente exercer uma força sobre as pessoas, envolvendo até os mais indiferentes em suas tramas.

Para Daolio (1997) alguns comportamentos usuais nos estádios de futebol, fora deles seriam considerados descontextualizados, como as expressões verbais e xingamentos utilizados pelos torcedores: são considerados deselegantes e abusivos no convívio social diário. Esse autor ressalta que o contraste entre o que se permite verbalizar nos estádios e fora deles é ainda maior quando se refere às mulheres, cujo papel social é permeado por delicadeza e boas maneiras.

Estudiosos como Pimenta $(1997 ;$ 2004) vêm distinguindo ainda o comportamento do torcedor comum daqueles pertencentes às torcidas organizadas. O torcedor comum não demonstra paixão pelo time, tanto quanto o associado às torcidas organizadas, embora nos estádios, mesmo que fisicamente separados, cantem juntos as mais variadas canções. Apesar de alguns torcedores não filiados evitarem entoar melodias e refrões típicos das torcidas organizadas, ou que exaltam a violência, esses dois grupos têm em comum formas comportamentais de comemoração e também de reclamações.

Já os torcedores organizados provocam os times adversários e outras torcidas com ofensas verbais ou chamados diretos ao confronto físico, participando coletivamente de atos de vandalismo e depredação. (BUFORD, 1992; PIMENTA, 1997; RETTO, 1996). Para Brandão 
(1996), na "torcida organizada" destaca-se e toma vulto o movimento social de jovens em torno dessa organização, que difunde novas dimensões culturais e simbólicas no cotidiano urbano. Estas torcidas organizadas de futebol costumam estar associadas nos dias de hoje a gangues juvenis, nas quais a transgressão e a agressividade deliberada são características centrais, confirmadas pelas imagens e interpretações veiculadas nos meios de comunicação.

Enquanto o torcedor comum é mero espectador numa partida, o "torcedor organizado" considera-se parte, quando não o próprio espetáculo. Para Pimenta (1997), o torcedor expressa no grupo sua masculinidade, seus sentimentos de solidariedade, de companheirismo e de pertencimento a esse agrupamento; ainda nesse agrupamento, ele assume a identidade do coletivo, relevando seus próprios valores em nome de algo considerado maior que ele mesmo. Segundo Hall (2002), esse agrupamento é provisório, com elementos heterogêneos, unidos pontualmente no futebol, numa partida do jogo, que determina uma forma de agir quando unido, e outra forma diversa, quando seus componentes são analisados isoladamente.

De acordo com a visão de Pimenta (1997; 2004), encontra-se nas torcidas organizadas uma estrutura típica do exército, com um espaço institucionalizado - inclusive com firma reconhecida em cartório -, hierarquia, controle, disciplina, regras de conduta e relações burocráticas. A diferença estabelece-se no fato de haver, nestes grupos de torcidas, eleições bianuais e pagamento de mensalidade pelos associados. Assemelha-se a outras relações sociais, nos quais o jovem também se sente acolhido, ouvido e respeitado, ainda que pratique a transgressão da ordem social estabelecida (PIMENTA, 1997; 2004).

Para Cunha (2006), o futebol torna-se um espaço de ritualização de uma violência não expressa no cotidiano.

A descarga de energia negativa depende de estímulos provocadores externos e quanto mais tempo este estímulo não aparece, mais o organismo irá procurá-lo (FREUD, 1930/1993).

Reis (2006) argumenta que os investimentos exorbitantes realizados no mundo do futebol podem ter incentivado o aumento da violência no esporte nas últimas décadas. Confrontos violentos entre torcidas organizadas não ocorrem ao acaso. A utilização da tecnologia da informação e comunicação permite que a organização das manobras das "torcidas organizadas" torne-se mais aprimorada, especializada, verdadeira operação de guerra. 
Assim, tais manifestações são programadas, baseadas em estratégias militares, envolvendo: ação de batedores, linha de frente, retaguarda, caças e emboscadas; além de materiais como bombas de fabricação caseira, armas de fogo, estiletes, canivetes e outros objetos capazes de causar ferimentos graves. Esses conjuntos de estratégias e armamentos fazem parte do cotidiano das torcidas organizadas e são utilizados contra o adversário sempre que os agressores julgarem necessário. Nesse espaço, explica Reis (2006), as ações individuais dos jovens têm ressonância e angariam o respeito do grupo.

Santos (2004) defende que o time ainda é a primeira razão para que esses torcedores se afiliem às torcidas e que a violência só deixou as torcidas organizadas mais visíveis para aqueles que queriam companhia para torcer. Acompanhando e analisando torcidas organizadas de dois grandes times paulistas (Palmeiras e Corinthians), Santos o autor assim concluiu:

\begin{abstract}
A maioria dos jovens que fazem parte das organizadas é composta por jovens adultos e adolescentes que moram na periferia de São Paulo. São inúmeros os motivos que fazem os torcedores se associarem às organizadas. Alguns me disseram que era porque "tocavam instrumentos e adoravam participar das festas que elas faziam nos estádios"; outros salientaram que "se sentiam mais torcedores do que aqueles que não são sócios das organizadas"; algumas moças falaram que "entraram na organizada porque os rapazes não mexem com elas, tampouco deixam que outros torcedores as desrespeitem nos estádios"; grande parte me falou da amizade e do acolhimento que eles encontram. Em suma, pelo que pude perceber, a grande maioria, se reúne nessas torcidas para fazer amigos e se sentir parte da sociedade (SANTOS, 2004, p. 93).
\end{abstract}

Nessa análise, Santos (2004) salienta a questão das torcidas organizadas tornarem-se espaço para os excluídos, conclusão corroborada por Pimenta (1997). Ainda para Santos (2004), a torcida é um símbolo a mais para os torcedores, que têm pela organizada uma paixão semelhante à que têm pelo time, trajando camisetas e bonés que os uniformizam, temendo mais perder a camisa em confrontos, do que a própria briga. Trazendo esses símbolos, imprimem a diferença entre eles e os outros torcedores.

\title{
4 Contribuição teórica de Freud
}

No texto "Psicologia de grupo e análise do ego", Freud (1921/1980) pondera, na parte inicial, estudos de dois teóricos: Le Bon (1912) e McDougall (1920/2005), observando a similaridade de fenômenos 
como inibição do intelecto do indivíduo, intenso aumento da afetividade e aumento da sugestionabilidade em situações grupais. Do mesmo McDougall, Freud (1921/1980) destaca, sobre as formações grupais, os pressupostos básicos que caracterizam uma reunião de pessoas como grupo. Destacam-se três dessas características: a) possuir um ideal que os una, b) apresentar uma interação sob a forma de rivalidade com grupos semelhantes e c) contar com uma estrutura hierárquica bem definida. Estudando-se o movimento das torcidas organizadas, é perceptível a presença dessas três características.

Embora possa praticar atos de vandalismo quando isolado, o indivíduo normalmente participa dessas ações violentas quando em grupos. Isto se explica pela possibilidade de utilizar a proteção do grupo para se fortalecer, superando o medo. Dessa forma, são explicados os comportamentos agressivos das torcidas de futebol.

A Psicologia de massas para Freud (1930/1993) é a parte da Psicologia Social voltada ao estudo do indivíduo enquanto membro de uma raça, nação, profissão, instituição ou multidão unidos para fins e objetivos determinados. O indivíduo apresenta, em situações específicas, o que Freud denominou de instinto social, promovendo comportamentos peculiares para tal situação. Ainda segundo o autor, tais situações e comportamentos específicos a situações coletivas, denomina-se grupo psicológico:

É um ser provisório, formado por elementos heterogêneos, que por um momento se combinam, exatamente como as células que constituem um corpo vivo, formam, por sua reunião, um novo ser que apresenta características muito diferentes daquelas obtidas por cada célula isoladamente (FREUD, 1930/1993, p. 83).

Esses comportamentos ocorrem pela coesão do grupo, que por sua vez é garantida, segundo Freud (1930/1993), quando os indivíduos são contagiados pelos comportamentos do grupo, por meio de um instinto de harmonização com a maioria. A força desse comportamento tem relação direta com a quantidade de pessoas que o repetem, bem como, o movimento é intensificado pela interação e excitação mútuas.

A contribuição da psicanálise na compreensão das relações sociais que se observam em situações de tensão fundamenta-se na idéia de que:

Persiste o fato de que ela descobriu tensões relacionais que parecem desempenhar em todas as sociedades uma função basal, como se o mal-estar da civilização desnudasse a própria articulação da cultura com a natureza (LACAN, 1950/1998, p. 129). 
Assim sendo, a função da lei é interditar o indivíduo na ação por impulso, responsabilizando-o pelos seus atos, e dando sentido às suas escolhas, por meio de um referencial simbólico que é o lugar próprio da lei.

É aí que a psicanálise, pelas instâncias que distingue no indivíduo moderno, pode esclarecer as vacilações da noção de responsabilidade em nossa época e o advento correlato de uma objetivação do crime para a qual ela pode colaborar (LACAN, 1950/1998, p. 129).

Em Totem e Tabu (1913/1980), Freud trata a cultura totêmica como referencial, para explicar que os filhos adotam os preceitos dos tabus como mecanismo de manutenção da sociedade, ao instituir suas bases legais. Assim, os tabus serviam como forma de proteção da comunidade, tidos como parte dos mais antigos mecanismos de ordenação do contexto social. Por exemplo, a lei contra o incesto salva os filhos de sua própria morte, a fim de restabelecer sua relação com o pai. O sistema totêmico foi, comparativamente, um pacto com o pai. Nesse pacto, o pai Ihes prometia proteção, cuidado e indulgência, tudo o que a imaginação infantil pode esperar de um pai. Por seu lado, os filhos se comprometiam a respeitar a vida paterna, deixando de repetir o ato que causara a destruição desse pai (FREUD, 1913/1980, p. 173).

Observa-se que a lei é estabelecida como forma de ordenar o convívio social, mantendo um pacto entre os membros do grupo, representado pelo pai. Freud $(1923 / 1980)$ constituiu o superego como representante da lei paterna e que tem a função de estabelecer limites ao sujeito, interditando-o na realização de seus desejos. Age assim como amparo da vida psíquica, com o papel de proibir o ego de realizar tudo o que deseja. Entretanto, sempre escapa algo ao sujeito, que pode terminar em ato de violência. (LACAN, 1963/2005). Isto ocorrendo, é com significativo prejuízo que o sujeito vive esse momento em que estabelece uma relação de banalização do próximo - no qual tenta realizar sua cruel agressividade - (FREUD, $1930 / 1980$ ), pois esse próximo é habitado profundamente pela maldade. A tarefa de amar esse próximo que lhe é estranho não é passível de realização, tornando adequada a proposta freudiana: "Ama a teu próximo como este te ama" (FREUD, 1930/1980, p. 132). Nesse sentido, "a lei não é capaz de deitar a mão sobre as manifestações mais cautelosas e refinadas da agressividade humana" (FREUD, 1930/1980, p. 134), o que afeta o convívio social harmônico.

O narcisismo das pequenas diferenças aparece no texto de Freud (1930/1993) como decorrente da agressividade pulsional, que 
impede o amor e a organização de um grupo independente da existência de outro grupo rival, no qual as tensões agressivas seriam descarregadas. Nesse sentido, considera-se o ódio como condição necessária para o amor, hipótese que descarta a possibilidade de paz. Os confrontos dos torcedores deixam a impressão de ter como motivo para suas ações um certo narcisismo das pequenas diferenças. Esses torcedores disputam com os que não pertencem ao seu grupo e que referenciam grupos ou referenciais diferentes.

Goffman (2005), pesquisando o tema em questão, conclui que o desempenho do líder nesses grupos acaba por imprimir demasiada organização nas torcidas, tornando-as instituições, provendo-as de espaços físicos muito amplos, com prestação de serviços aos associados, como academia de ginástica, lojas, lanhouses, campanhas sociais e bolsa de empregos. Por suprirem boa parte de suas necessidades nas sedes das torcidas, os participantes restringem seu contato com outros grupos e pessoas, numa espécie de confinamento, fato que pode agravar ainda mais a rivalidade com outras torcidas diferentes. Nesse entendimento, Freud (1921/1980) explica que a forma de estrutura eleva o padrão moral estabelecido entre os grupos e reduz a capacidade intelectual, tornando uma posição crítica de seus membros cada vez mais rara. Nesta hipótese, a violência pode emergir, parecendo incompreensível aos não participantes daquele grupo.

Analisando grupos como a igreja e o exército, Freud (1921/1980) reconhece em ambos, apesar de suas diferenças, um cabeça (líder), a quem atribui um poder "misterioso e irresistível" incentivando disputas ou tréguas e com certa força que impele os membros do grupo a se unirem, com castigos para tentativas de dissolução grupal. Freud admite que tal líder possa ser representado através de uma idéia, uma abstração ou um desejo.

Dessa forma, nas torcidas, a concretização dos atos violentos está relacionada ao desejo do líder e de sua postura diante da torcida que conduz. As relações amorosas são sublimadas nos grupos. Os objetivos das pulsões sexuais são desviados. Para Freud, tais pulsões são gradações do estado amoroso nas quais ocorre uma "certa usurpação do ego" (FREUD, 1921/1980).

Podemos afirmar que um time de futebol começa a ser amado antes da transferência desse amor para os integrantes da sua torcida. A reflexão freudiana sobre o "estar amando" é iniciada com o estudo da identificação, que trata de laços emocionais difíceis de descrever. Esse estudo da identificação permite melhor entendimento do grupo. Em nosso estudo, a identificação pode levar em conta como se chega a ser torcedor de um time, e a amar um clube, o que também é difícil de descrever.

Identificação é a expressão de laço emocional mais primitiva. Começa com o garoto que quer incorporar o pai de certa forma ao identificar- 
se com ele. O pai é idealizado como o modelo. O enriquecimento do ego aparece na identificação pela atribuição de características do objeto ao sujeito. Esse é um tipo de relação amorosa em que há fascinação e até servidão, com uma entrega do sujeito ao objeto, no qual o sujeito tem seu constituinte mais importante substituído pelo objeto (FREUD, 1921/1980).

A força e os aspectos da grandeza do clube esportivo e de sua torcida, junto com a busca constante pela vitória, levam a um ego que pode ser consumido por esse objeto. Na busca pelo ideal da vitória, os impulsos de natureza sexual perdem impacto e mudam de conotação. O objeto sobe de plano e o ego torna-se mais modesto, até ser consumido pelo objeto. O lugar do ideal do ego passa a ser reverenciado pelos valores do objeto. Mesmo quando a realidade de um time de futebol indica que tudo está ruim com os jogadores, com a diretoria, com o técnico, o time em si, como entidade, ainda aparece idealizado e positivo na opinião de seus torcedores.

\begin{abstract}
A crítica exercida por essa instância silencia; tudo que o objeto faz e pede é correto e inocente. A consciência não se aplica a nada que seja feito por amor do objeto; na cegueira do amor, a falta de piedade é levada até o diapasão do crime. A situação total pode ser inteiramente resumida numa fórmula: o objeto foi colocado no lugar do ideal do ego (FREUD, 1921/1980, p. 143).
\end{abstract}

\title{
5 Conclusão
}

Na definição da seleção e escolha de um time, tradicionalmente, a tendência dos filhos era pelo time de opção do pai, familiares ou de alguém considerado. Atualmente, há que se acrescentar a esses fatores, o poder das mídias, promovendo e divulgando times vencedores e jogadores consagrados, interferindo decisivamente na definição da opção do torcedor. Os diversos campeonatos, em âmbito regional, nacional e mundial, fomentam rivalidades e geram frustrações e alegrias aos torcedores.

Seja no estádio, torcendo e cantando os gritos de sua torcida organizada, em bares, reunindo-se em casas, ou isoladamente em sua televisão ou outras mídias, o torcedor vivencia um mundo muito similar ao do cotidiano. Em um somatório de ideias racionais e irracionais, o clube tem um papel central, motivando os torcedores a uma manifestação favorável ou contrária ao seu desempenho.

$\mathrm{Na}$ sociedade atual, o estado de impunidade e ilegalidade estimula atos nos quais perdem o significado tanto o amor do outro como a possibilidade de uma punição: isto é, bem e mal tornam-se similares. Assim, "o perigo só se instaura, se e quando a autoridade descobri-lo, 
e, em ambos, a autoridade se comporta da mesma maneira" (FREUD, $1930 / 1980$, p. 148).

Em uma sociedade que busca satisfação pessoal, prazer e realização de desejo ao invés de uma ordem, com uma lei que não se sustenta, a violência serviria como meio de fuga do sujeito frente aos seus impasses, sendo ele algumas vezes o agressor e em outras, a vítima.

É, pois, um princípio geral que os conflitos de interesses entre os homens são resolvidos pelo uso da violência. É isto que se passa em todo o reino animal, do qual o homem não tem motivo por que se excluir (FREUD, 1933/1980, p. 246).

Observando-se o universo dos times brasileiros e os grandes números de partidas que se realizam semanalmente, por conta dos campeonatos, há que se concordar com Murad (2007), para quem o futebol não é em essência um esporte violento, "embora haja práticas de violência dentro e fora do campo" (MURAD, 2007, p.21).

Portanto, refletir sobre violência e seu desenvolvimento implica necessariamente incluir todos os aspectos sociais, culturais, econômicos e, sobretudo a educação, que têm influência no comportamento violento, podendo este, entretanto, ser modificado num contexto sedimentado na justiça social.

Este estudo pretende provocar e contribuir com um novo olhar na aplicação de idéias da psicanálise ao âmbito esportivo - a violência relacionada ao futebol -, propiciando a produção de novos conhecimentos.

A bibliografia consultada reconhece o futebol como elemento de expressão e significância da cultura brasileira, permitindo a possibilidade de interpretação da violência no esporte à luz da psicanálise, uma vez que o futebol é fator de permissão de transgressão da ordem social estabelecida, bem como a interação e excitação propiciadas nos estádios destacam-se como elementos de coesão grupal, reforçando comportamentos agressivos das torcidas organizadas.

Já do ponto de vista metodológico, o presente estudo define-se como uma pesquisa bibliográfica, cujo universo envolve compreensão e explicação do tema com base exclusiva na bibliografia especializada das diferentes áreas que estudam o tema, sendo esta sua principal limitação.

Como sugestão para novos desdobramentos desta pesquisa, uma idéia é realizar estudos que confrontem as premissas freudianas em comparação com outras teorias psicológicas que busquem explicar e cotejar o comportamento individual ao comportamento do indivíduo em multidões e em grupos organizados, com objetivos específicos. 


\section{Referências}

ASSIS, T. C. F. A Representação Social da Violência em Torcidas Organizadas de Futebol. 2008. 131f. Dissertação (Mestrado em Psicologia) - Universidade Católica de Goiás, 2008.

BRANDÃO, I. L. São Paulo Futebol Clube: Saga de um campeão. São Paulo: DBA, 1996.

BUFORD, B. Entre os vândalos. São Paulo: Schwarcz, 1992.

CUNHA, F. A. Torcidas no Futebol: Espetáculo ou Vandalismo? São Paulo: Scortecci, 2006.

DAOLIO, J. O drama do futebol brasileiro - uma análise sócioantropológica. Revista Paulista de Educação Física, 1997.

FREUD, S. Totem e Tabu. In: Edição Standard brasileira. Obras psicológicas completas de Sigmund Freud. Rio de Janeiro: Imago, 1913/1980.

FREUD, S. Psicologia de Grupo e Análise do Ego. In: Edição Standard brasileira. Obras psicológicas completas de Sigmund Freud. Rio de Janeiro: Imago, 1921/1980.

FREUD, S. O ego e o id. In: Edição Standard brasileira. Obras Completas de Sigmund Freud, v. 19. Rio de Janeiro: Imago, 1923/1974e, p. 15-80.

FREUD, S. O mal-estar na civilização. In: Edição Standard brasileira. Obras psicológicas completas de Sigmund Freud. Rio de Janeiro: Imago, 1930/1993, p. 73-148.

FREUD, S. Por que a Guerra? In: Edição Standard brasileira. Obras psicológicas completas de Sigmund Freud. Rio de Janeiro: Imago, 1930/1980.

GOFFMAN, E. Manicômios, Prisões e Conventos. São Paulo: Perspectiva, 2005.

HALL, S. A identidade em questão. Rio de Janeiro: DP\&A, 2002.

LACAN, J. Escritos. I ntrodução teórica às funções da psicanálise em criminologia. Tradução V. Ribeiro. Rio de Janeiro: Jorge Zahar, 1950- 1998.

LACAN, J. O Seminário, livro 10: passagem ao ato e acting out. Tradução V. Ribeiro. Rio de Janeiro: Jorge Zahar, 1963-2005.

LE BON, G., La Révolution française et la psychologie des révolutions. Paris, Flammarion, 1912.

MARIN, I. S. K. Violências. São Paulo. Escuta: 2002.

MCDOUGALL, W. The Group Mind. Whitefish, MT: Kessinger Publishing. 2005. (original 1920).

MURAD, M. A violência e o futebol: dos estudos clássicos aos dias de hoje. Rio de Janeiro: FGV, 2007.

MURPHY, P., WILIAMS, J.; DUNNIN, E. O futebol no banco dos réus: violência dos espectadores num desporto em mudança. Oeiras/Portugal: Celta Editora, 1994. 
PIMENTA, C. A. M. Torcidas organizadas e futebol: violência e auto-afirmação - aspectos da construção das novas relações sociais. Taubaté, SP: Vogal, 1997.

PIMENTA, C. A. M. Torcidas organizadas: brutalidade uniformizada no Brasil. IN PINSKY C. B. (Orgs.). Faces do Fanatismo. São Paulo: Contexto, 2004, p. 262-81.

PRADO, D. A. Dois textos: Tempo (e espaço) no futebol. Revista USP, São Paulo, n. 22, p.18-29, jun./jul./ago. 1994.

REIS, H. H. B. Futebol e violência. Campinas, SP: Armazém do I pê, 2006.

RETTO, A. B. A. Multidão sem rosto. In: LERNER, J. (Org.). A violência no esporte. São Paulo: I mesp, 1996. p. 39-44.

SANTOS, T. C. Dos espetáculos de massa às torcidas organizadas: paixão, rito e magia no futebol. São Paulo: Annablume, 2004.

\section{Endereço para correspondência}

\section{Gustavo Hermínio Salati Marcondes de Moraes}

Rua Maria Antônia, 130, apt. 708, Vila Buarque, CEP 01222-010, São Paulo - SP, Brasil

Endereço eletrônico: gustavo.moraes@gvmail.br

Olga Maria Salati Marcondes de Moraes

Rua Alfredo Patelli, 61, Jardim São Paulo, CEP 18051-880, Sorocaba - SP, Brasil

Endereço eletrônico: olgasalati@uol.com.br

Recebido em: 09/08/2010

Reformulado em: 22/11/2010

Aceito para publicação em: 25/11/2011

Acompanhamento do processo editorial: Deise Mancebo

\section{Notas}

* Doutorando em Administração de Negócios na Escola de Administração do Estado de São Paulo, Fundação Getúlio Vargas - FGV. Professor da Fundação Escola de Comércio Álvares Penteado.

**Pedagoga pela UNESP - Rio Claro, especialista em gestão educacional. 